\title{
Dimebolin in Dementia
}

\author{
Deepak Sachdeva ${ }^{1}$ \& Alistair Burns ${ }^{2}$ \\ 1 Moor Side Unit, Trafford General Hospital, Urmston, Manchester, UK \\ 2Psychiatry Research Group, University of Manchester, Manchester, UK
}

\author{
Keywords \\ Alzheimer's disease; Dementia; Dimebolin; \\ Dimebon; Memory. \\ Correspondence \\ Deepak Sachdeva, M.B.B.S., M.R.C.Psych., \\ Moorside Unit, Trafford General Hospital, \\ Urmston, Manchester, UK. \\ Tel.: +44 161746 2650; \\ Fax: +44 161746 2707; \\ E-mail: sachdeva.d@gmail.com
}

doi: $10.1111 / j .1755-5949.2010 .00156 . x$
The treatment options for Alzheimer's type dementia are limited to the use of acetyl-cholinesterase inhibitors, along with memantine in some cases, and offer variable success in the treatment of cognitive impairment and to improve or stabilize activities of daily living, behavioral abnormalities, and impairment of global function. This review examines dimebolin, a nonselective antihistamine drug that has been used in Russia in the past for its antihistamine effect and has now generated considerable interest in the treatment of Alzheimer's type dementia, following results in the initial trials (Doody et al., 2008) and is currently under further evaluation. This article considers various theories proposed to explain its effect in the treatment of dementia. The results from further trials will help to clarify the future of dimebolin as a potential treatment for chronic neurodegenerative disorders that include dementia that affects 25 million people worldwide.

\section{Introduction}

Dimebolin hydrochloride (proposed generic name: Latrepirdine; brand name: Dimebon $\left.{ }^{\circledR}\right)$, is chemically 2,3,4,5-Tetrahydro-2,8-dimethyl-5-(2-(6-methyl-3pyridyl)ethyl)-1H-pyrido(4,3-b)indole. It was initially used in Russia in 1983 as a nonselective antihistamine for the treatment of skin allergy and allergic rhinitis but eventually its use as an antihistamine declined when more selective drugs were discovered [1-2].

A recent study by Doody et al. [3] has generated renewed interest in the drug. In this study dimebolin appeared to have significant clinical effect on various symptom domains of Alzheimer's type dementia. Currently, at least three studies are being performed to examine this effect further.

\section{Current Dementia Treatments}

Dementia is a term used to describe a cluster of symptoms affecting not only memory but a number of other domains including communication, reasoning, judgment, agitation, and functional impairment that are progressive and generally irreversible. Many patients may also display psychotic or depressive symptomatology and changes in behavior (Behavioral and psychological symptoms of dementia) [4].

Alzheimer's disease is the most common type of dementia. It has been estimated that $16 \%$ of aging population above 80 years old and $7 \%$ of those above the age of 65 have some form of dementia; this means that there are 700,000 people with dementia within the UK and the cost of dementia is estimated to be more than $£ 17$ billion per year [5].

The underlying pathology in dementia syndromes may consist of various structural and biochemical changes. These changes may involve formation of neurofibrillary tangles and plaque formation (common but not exclusive) in those with Alzheimer's type dementia and microinfarcts in those with vascular dementia [6]. Some of these changes occur with aging albeit with much less severity [7]. Furthermore, in those with lacunar infarcts in the basal ganglia, thalamus, or deep white matter, fewer neuropathological lesions of Alzheimer's type could lead to dementia, compared with those without infarcts [8].

The biochemical changes can involve deficits in a number of neurotransmitters affecting cholinergic transmission and these deficits are more noticeable in the nuclei of basolateral group in Alzheimer's type dementia [9]. The cholinergic hypothesis was based on the reduction 
in acetylcholine in the brain and deficits in the activity of choline acetyltransferases, which correlates well with clinical dementia ratings [10] and became the basis for use of the first generation of antidementia drugs that block activity of acetylcholinestrase in the brain.

The current treatment options for Alzheimer's type dementia are limited in their magnitude of clinical effect as well as duration of action. Presently, in the United Kingdom, there are three cholinesterase inhibitors licensed for treatment of Alzheimer's type dementia, donepezil, rivastigmine, and galantamine. The clinical benefit with their use is modest and may last up to few years. They can produce numerous side effects ranging from mild gastrointestinal upsets, which are common, to more severe adverse effects that include gastric and duodenal ulcers, gastrointestinal hemorrhage, bradycardia, seizures, and AV block [11]. Together with higher incidence of medical comorbidity in this population, there can be several contraindications to their use. The cost/effect analysis guides that they should be used in patients with moderate degree of Alzheimer's type dementia as recommended in NICE UK guidance [12].

A systematic review of the partial glutamate receptor antagonist, memantine has shown a statistically significant improvement in Alzheimer's type dementia but clin- ically the magnitude of the improvement was marginal [13].

Apart from these, some other agents have also been studied for the treatment of dementia but have not been able to show clinically significant benefit [11]. These include Ginkgo biloba (small but statistically significant result in a meta-analysis [14], selegiline (only short-term low-magnitude clinical improvement in a systematic review) [15], estrogens (unsafe due to increased risk of thrombosis and no clear benefit) and NSAIDs (association between lower risk of $\mathrm{AD}$ and use of these drugs) [16] and Vitamin E [17].

\section{Dimebolin: Proposed Mechanism of Action}

Although several possible action pathways have been proposed for the clinical effect of dimebolin on neurodegenerative diseases including Alzheimer's type dementia, the actual mechanism remains poorly understood (Table 1).

There is some evidence suggesting that its mechanism of action involves $\mathrm{H}_{1}$ blockade [18]. This $\mathrm{H}_{1}$ blocking activity is 1.5 times stronger than promethazine but lacks

Table 1 Various action pathways of dimebolin affecting memory

\begin{tabular}{|c|c|c|}
\hline Pathway & Dose/concentration of dimebolin used & Study \\
\hline Mechanism involving $\mathrm{H}_{1}$ blockade & Data not available & Mateeva et al. 1983 \\
\hline $\begin{array}{l}\text { Inhibitory effect on the deamination in basal } \\
\text { ganglia and hypothalamus }\end{array}$ & $100 \mu \mathrm{M}$ in vitro & Shadurskaia et al. 1986 \\
\hline $\begin{array}{l}\text { Inhibits neurotoxin (AF64A)- induced } \\
\text { neurodegeneration }\end{array}$ & $1 \mathrm{mg} / \mathrm{kg}$ body weight injected intraperitoneally & Lermontova et al. 2000 \\
\hline $\begin{array}{l}\text { Protected cerebellar neurons against the action of } \\
\beta \text {-amyloid, anticholinestrase activity, } \\
\text { NMDA blocking activity, } \\
\text { inhibition of potential-dependent } \mathrm{Ca}^{2+} \text { uptake }\end{array}$ & $\begin{array}{l}25 \mu \mathrm{M} \text { concentration in cultured neurons; } \\
\mathrm{IC} 50=57 \mu \mathrm{M} \text { for effect on } \mathrm{Ca}^{2+} \text { uptake; IC50 = } 7.9 \\
\mu \mathrm{M} \text {; and } 42 \mu \mathrm{M} \text { for butyrylcholine esterase and } \\
\text { acetylcholine esterase, respectively; NMDA } \\
\text { blocking activity at EC50 }=42 \pm 6 \mathrm{mg} / \mathrm{kg} \\
\text { intraperitoneal }\end{array}$ & $\begin{array}{l}\text { Bachurin et al. } 2001 \\
\text { Lermontova et al. } 2001\end{array}$ \\
\hline Optimizing mitochondrial pore dysfunction & $200 \mu \mathrm{M}$ & Bachurin et al. 2003 \\
\hline $\begin{array}{l}\text { NMDA receptor antagonist at high concentrations, } \\
\text { and at low dose acts as positive modulator of } \\
\text { AMPA receptors }\end{array}$ & $\begin{array}{l}\text { Above } 6 \mu \mathrm{M} \text {, blocked NMDA- induced currents, } \\
\text { above } 0.2 \mu \mathrm{M} \text { for AMPA-modulating effect }\end{array}$ & Grigorev et al. 2003 \\
\hline $\begin{array}{l}\text { NMDA blocking and protective effects against } \\
\text { glutamate-induced apoptosis }\end{array}$ & $\begin{array}{l}\text { IC } 50=10 \mu \mathrm{M} \text { for NMDA blocking effects; and } \\
\text { higher concentration of } 50 \mu \mathrm{M} \text { for protection } \\
\text { against glutamate-induced }\end{array}$ & Wu et al. 2008 \\
\hline $\begin{array}{l}\text { Activity on } 5-\mathrm{HT}_{6} \text { receptors may affect short-term } \\
\text { memory }\end{array}$ & $\begin{array}{l}\mathrm{K}(\mathrm{i})=26.0+/-2.5 \mathrm{nM} \\
(\mathrm{IC} 50=0.89 \mu \mathrm{M})\end{array}$ & $\begin{array}{l}\text { Schaffhauser et al. 2009, Ivachtchenko } \\
\text { et al. } 2009\end{array}$ \\
\hline Increased expression of $\beta$-amyloid excretion & $\begin{array}{l}\text { Intraperitoneal injection } 3.5 \mathrm{mg} / \mathrm{kg} \text {, Extracellular } \\
\text { concentration of } 1-10 \mu \mathrm{M}\end{array}$ & Cirrito et al. 2009; Gandy et al. 2009 \\
\hline $\begin{array}{l}\text { Inhibitory effect on TDP-43 (TAR DNA binding) } \\
\text { protein aggregation in thrice-cloned } \\
\text { neuroblastoma cells }\end{array}$ & $5 \mu \mathrm{M}$ & Yamashita et al. 2009 \\
\hline
\end{tabular}


the sedative effects of drugs in this class (e.g., diphenhydramine and promethazine).

At concentration of $10^{-4} \mathrm{M}$, in vitro, dimebolin shows inhibitory effect on the deamination of amines (dopamine and benzylamine). However, in lower concentrations of dimebolin $10^{-5}$ to $10^{-6}$, this effect on MAO (monoamine oxidases) activity ceases. The inhibition of MAO activity resulting in increase in dopamine and noradrenaline was observed in basal ganglia and hypothalamus [19].

Another experimental study was conducted in rats treated with neurotoxic agent AF64A (1-ethyl-1-(2hydroxyethyl) aziridinium) that has high affinity for acetylcholine receptors and causes neuronal cell death. Dimebolin appeared to prevent neurodegeneration and was able to compensate for the disorder in learning that occurred due to the neurotoxin. The effect of both tacrine and dimebolin was beneficial on learning in this study [20].

Dimebolin protected cerebellar neurons against the action of beta amyloid and there was evidence of significant anticholinestrase activity for butyrylcholine esterase and acetylcholine esterase. It also appeared to have NMDA (N-methyl-D-aspartic acid) blocking activity (prevented NMDA-induced seizure activity in mice) [21]. Along with its inhibitory effect on beta amyloid that is a recognized pathological feature in Alzheimer's type dementia, the pathway involving inhibition of potential-dependent $\mathrm{Ca}^{2+}$ uptake may be involved in neuroprotective effect in cultured neurons [22].

Bachurin et al. explored the possible pathway of mitochondrial pore activity as this is thought to be involved in regulation of $\mathrm{Ca}^{2+}$ transport across mitochondrial membrane and some neurotoxins may permanently open these pores leading to degeneration of neurons. Dimebolin may be able to conserve the mitochondrial function by blocking neurotoxin-mediated mitochondrial pore dysfunction [23].

In cortical neurons, dimebolin affects polyamine site of NMDA (N-methyl-D-aspartic acid) receptor and at high concentrations, may become NMDA receptor antagonist. At lower dose it acts as positive modulator of receptors for artificial glutamate analogue, AMPA ( $\alpha$-amino3-hydroxy-5-methyl-4-isoxazolepropionic acid). Dimebolin's NMDA antagonistic effect is weaker than that of memantine [24].

In mice primary striatal neuronal cultures, dimebolin is an inhibitor of NMDA (N-methyl D-aspartate) receptors with half maximal inhibitory concentration $\left(\mathrm{IC}_{50}\right)$ being $10 \mu \mathrm{M}$. It also inhibited glutamate-induced increase in $\mathrm{Ca}^{2+}$ levels. At $50 \mu \mathrm{M}$ concentration, dimebolin showed significant protective effects against glutamate-induced apoptosis but lower concentration of dimebolin $(5 \mu \mathrm{M}$ and $10 \mu \mathrm{M}$ ) failed to show the same effect [25].

Dimebolin occupies $5-\mathrm{HT}_{6}$ receptors and this may have effect on short-term memory [26]. This effect of dimebolin on the serotonergic $5-\mathrm{HT}_{6}$ receptors is antagonistic and may be an important pathway for its beneficial effects on cognition [27].

Interestingly, the findings from another study recently presented at International Conference on Alzheimer's disease, Vienna, Austria (July 2009), which examined the molecular effects of dimebolin on mouse neuroblastoma cells observed increased release of beta amyloid from nerve terminals; this is very surprising as beta amyloid deposition has been linked to pathogenesis of Alzheimer's type dementia. Increased levels of beta amyloid release from isolated nerve terminals were not expected results for a drug aimed to treat Alzheimer's type dementia [28].

Dimebolin was found to have inhibitory effect on TDP43 (TAR DNA binding) protein aggregation in thricecloned neuroblastoma cells. At $5 \mu \mathrm{M}$ concentration, dimebolin reduced protein aggregation by $45 \%$. The TDP43 pathology is a recognized finding in neurodegenerative diseases like amyotrophic lateral sclerosis and fronttemporal lobar degeneration [29] and this effect may indicate potential benefit in other neurodegenerative diseases as well.

\section{Dimebolin: Evidence of Clinical Effect in DAT (Original Study by Doody et al.)}

Doody et al. conducted a randomized placebo-controlled double-blind trial of 183 patients with mild-to-moderate Alzheimer's type dementia (mini-mental state examination [MMSE] scores 10-24) at 11 sites in Russia, who were given oral dimebolin, $20 \mathrm{mg}$ three times a day (60 mg/day) and were not given access to any other antidementia medications [3].

The outcome measures included assessment of cognition (ADAS-cog and MMSE), functional assessment (ADCS-ADL), and behavior (NPI) (Figure 1). The primary analysis showed significant benefit as measured on ADAS-cog in the patients who completed the trial. This benefit at week 26 was -4.0 on ADAS-cog (mean drugplacebo difference [95\% CI -5.73 to -2.28 ]; $P<0.0001$ ). One hundred thirty-four patients (68 in dimebolin group, 66 in placebo group) enrolled in the 6-month blinded extension phase of the study that showed further benefit (at week 52) for those on dimebolin when compared to benefit achieved at week 26 on dimebolin and also when compared to placebo. (-6.9 compared to placebo at 1 year). The improvement in neuropsychiatric symptoms that had been achieved at week 26, was maintained 


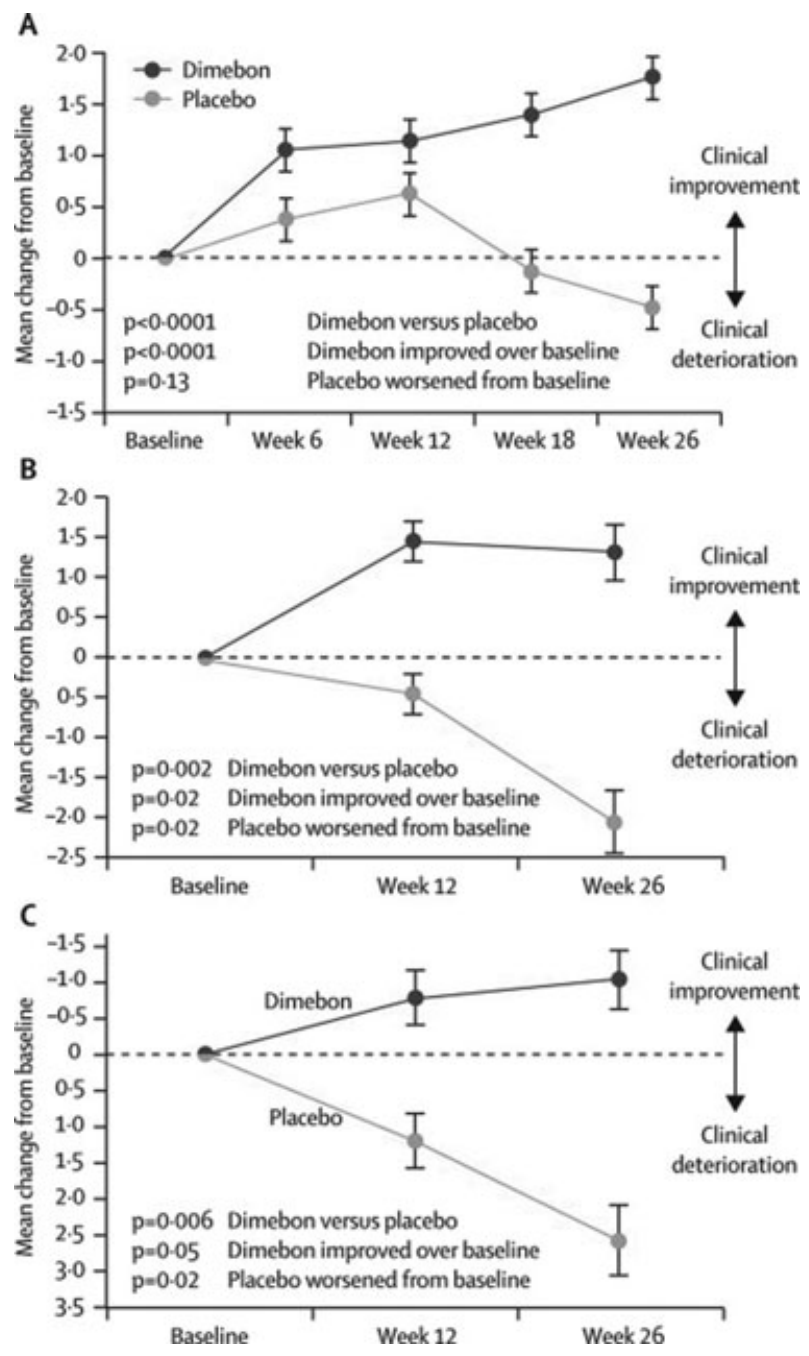

Figure 1 Mean change in the MMSE (A), ADCS-ADL (B), and NPI (C) from baseline to week 26;MMSE, mini-mental state examination. ADCS-ADL, Alzheimer's disease cooperative study - activities of daily living. NPI, neuropsychiatric inventory. Error bars show SE (with permission from Doody et al.) at 1 year (Table 2), as measured by NPI. There was slight improvement shown on Clinician's Interview-based Impression of Change plus Caregiver Input (CIBIC plus) and functional assessment (ADCS ADL), but this was found to be statistically insignificant.

The occurrence of adverse effects was similar in dimebolin and placebo groups and the most common side effects were dry mouth, depressed mood, or depression in $14 \%$ patients. This compares to dimebolin's adverse effect in concert study (dimebolin with donepezil vs. placebo) where the commonest adverse effects were fatigue, abdominal distension, and falls [30].

It is not clear if the placebo-treated patients (in clinical studies) of Alzheimer's type dementia get significantly different care in Russia from those in other parts of the world.

\section{Current Trials of Dimebolin}

There are two trials examining dimebolin in dementia, one with concurrent use of donepezil and another is placebo-controlled study. There are also studies evaluating its possible benefit in other neurodegenerative disorders, for example, Huntingdon's disease.

Medivation is currently doing Phase 3 clinical trial of dimebolin in Alzheimer's type dementia (The Connection Study) in the United States. http://www.connectionstudy.com/) this study has completed enrolling patients for Phase 3 trial of dimebolin in patients with mild-to-moderate Alzheimer's type dementia. This is an international, double-blind, placebocontrolled safety and efficacy study and is designed to confirm the positive findings of the former dimebolin study that showed statistically significant improvements over placebo in memory, thinking, activities of daily living, behavior, and overall function. This study enrolled patients at sites in the United States, Europe, and South America.

Table 2 Summary of effects of dimebolin on primary outcomes measures at 6 and 12 months LOCF, last observation carried forward (data with permission from Doody et al. [3])

\begin{tabular}{lllll}
\hline & Dimebolin $6 \mathrm{mn}$ & Difference from placebo at 6 months & Dimebolin at 12 months & Difference from placebo at 12 months \\
\hline ADAS-Cog & $-1.9(-2.92$ to -0.85$)$ & $-4.0(-5.73$ to $-2.28 ; P<0.0001)$ & $-0.9(-2.05$ to 0.23$)$ & $-5.5(-7.56$ to $-3.51 ; P<0.0001)$ \\
MMSE & $1.8(1.14$ to 2.39$)$ & $2.2(1.37$ to $3.12 ; P<0.0001)$ & $0.7(-0.05$ to 1.44$)$ & $2.1(1.04$ to $3.21 ; P=0.0002)$ \\
ADCS ADL & $1.3(-0.09$ to 2.70$)$ & $3.4(1.27$ to $5.42 ; P=0.002)$ & $-0.4(-2.0$ to 1.2$)$ & $4.4(1.79$ to $6.99 ; P=0.0014)$ \\
NPI & $-1.0(-2.62$ to 0.56$)$ & $-3.6(-6.05$ to $-1.08 ; P=0.006)$ & $0.6(-1.34$ to 2.60$)$ & $-3.3(-6.10$ to $-0.45 ; P=0.0201)$ \\
CIBIC plus & $3.7(3.52$ to 3.91$)$ & $0.6(-0.92$ to $-0.31 ; P<0.0001)$ & $4.0(3.83$ to 4.26$)$ & $-0.7(-0.98$ to $-0.31 ; P=0.0014)$ \\
\hline
\end{tabular}

For MMSE and ADCS-ADL, higher scores indicate better performance. For ADAS-cog, CIBIC-plus, and NPI, higher scores indicate worse performance. ADAS-cog, Alzheimer's disease assessment scale-cognitive subscale; MMSE, mini-mental state examination; ADCS-ADL, Alzheimer's disease cooperative study-activities of daily living; NPI, neuropsychiatric inventory; CIBIC-plus, clinician's interview-based impression of change plus caregiver input. 
The Concert study (sponsored by Medivation, Inc. and Pfizer Inc.) is aimed at evaluation of effects of dimebolin when given in addition to donepezil for 12 months compared to placebo and donepezil. This Study is in Phase 3 trial. The Phase 1 data showed that the dimebolin was well tolerated when used in combination with donepezil [30].

The DIMOND trial, which is a randomized, doubleblind, placebo-controlled Phase 2 trial, is taking place at some 15 research centers in the United States and United Kingdom and it completed recruitment in 2008. It will evaluate effect of dimebolin on Huntingdon's disease, another neurodegenerative disease.

\section{Discussion}

Cognition has been assessed using ADAS cog on a scale of 0-70 with increased score indicating more severe impairment in cognition [31].

In a Cochrane review, the effect of donepezil compared to placebo showed benefit as measured on Adas Cog difference of -2.80 points, MD 95\% CI -3.74 to -2.10 , $(P<$ $0.00001)$ [32]. There was a difference of 4 points [95\% CI -5.73 to -2.28 ] at 26 weeks when dimebolin was compared with placebo [3], which suggests that dimebolin is at least as effective as donepezil in the treatment of Alzheimer's type dementia.

Although the $\mathrm{Ca}^{2+}$ stabilizing effect may explain some of the biochemical effects in these cultures, this required a higher concentration of $50 \mu \mathrm{M}$. In studies on patients with Alzheimer's type dementia by Doody et al., with patients receiving $20 \mathrm{mg}$ tablets, the concentrations are likely to be lower than $0.6 \mu \mathrm{M}$, which raises doubt whether this pathway is responsible for its clinical effects and therefore the foremost mechanism of clinical effect is likely to be either based on $\mathrm{H}_{1}$ histamine blockade (which requires low concentrations, with half maximal inhibitory concentration IC $50=3.4 \mathrm{nM}$ ) or an unknown pathway [25].

Further evaluation of long-term effects of dimebolin on extracellular levels of $\beta$-amyloid is also required following the interesting finding that in the short-term dimebolin increases levels of $\beta$-amyloid, which does not fit well with current understanding of pathogenesis of dementia [33].

\section{Conclusion}

Taking into account that the burden of dementia is steadily increasing, it is crucial to investigate new treatment strategies that are effective against cognitive and other symptoms of Alzheimer's type dementia. Several different strategies are being tested in parallel, for example, active immunization against amyloid- $\beta 42$ (A $\beta$ ) as a treatment for Alzheimer's type dementia. Dimebolin seems to be able to take up the challenge and it is yet to be seen if this evolves as a useful treatment alternative.

In drug safety studies conducted with animals, it appears to have no local irritating effects on gastrointestinal system and at levels up to $5 \mathrm{mg} / \mathrm{kg}$ had no significant toxic effects on rats guinea pigs and dogs when given in the dose of $5 \mathrm{mg} / \mathrm{kg}$, and caused reversible changes in liver and kidney at higher dose of $10 \mathrm{mg} / \mathrm{kg}$ and $70 \mathrm{mg} / \mathrm{kg}$ [34]. In human studies completed so far the side effect profile is not much worse than current treatment options available.

It is possible that $\mathrm{H}_{1}$ blockade may be an important pathway but limited data on $\mathrm{H}_{1}$ blockade affecting memory informs otherwise. There is some evidence from animal studies that impairment of working memory function with clozapine is linked to $\mathrm{H}_{1}$ receptor antagonism [35] and that the pharmacological blockade of $\mathrm{H}_{1}$ receptors (using pyrilamine, a selective $\mathrm{H}_{1}$ receptor antagonist) induce deficits in working memory [36] with marginal improvement in reference memory on the 16 -arm radialarm maze (RAM) in rats [35].

Despite of lack of clarity about the exact pathway involved, the clinical effect appears significant. Good tolerability and safety profile of dimebolin warrants its further examination. Further research would help to confirm clinical efficacy, tolerability, and examine molecular mechanisms of its actions in greater depth, which will help improve understanding of neurodegenerative diseases like Alzheimer's type dementia.

\section{Conflict of Interest Statement}

$\mathrm{AB}$ accepts consultancy fees from Pfizer, Eisai, Lundbeck, Shire and Janssen pharmaceutical.

\section{References}

1. Molecule of the month. Dimebolin hydrochloride. Drug News Perspect 2007;20:467.

2. Burns A, Jacoby R. Dimebon in Alzheimer's disease: Old drug for new indication. Lancet 2008;372:179-180.

3. Doody RS, Gavrilova SI, Sano M, et al. Effect of dimebon on cognition, activities of daily living, behaviour, and global function in patients with mild-to-moderate Alzheimer's disease: A randomised, double-blind, placebo-controlled study. Lancet 2008;372:207-215.

4. Burns A, Iliffe S. Alzheimer's disease. BMJ 2009;338: 179-180.

5. Alzheimer's Society 2007, Dementia UK report, London 2007. http://alzheimers.org.uk/site/scripts/download_ info.php?fileID=1 [Accessed March 30, 2010].

6. Brayne C, Richardson K, Matthews FE, et al. Neuropathological Correlates of Dementia in Over-80Year-Old Brain Donors from the Population-Based 
Cambridge City over-75s Cohort (CC75C) Study. J Alzheimers Dis 2009; 18:645-658.

7. Lewis H, Beher D, Cookson N, et al. Quantification of Alzheimer pathology in ageing and dementia: Age-related accumulation of amyloid-beta(42) peptide in vascular dementia. Neuropathol Appl Neurobiol 2006;32: 103-118.

8. Snowdon DA, Greiner LH, Mortimer JA, Riley KP, Greiner PA, Markesbery WR. Brain infarction and the clinical expression of Alzheimer disease. The Nun Study. JAMA 1997;277:813-817.

9. Sahin HA, Emre M, Ziabreva I, Perry E, Celasun B, Perry $\mathrm{R}$. The distribution pattern of pathology and cholinergic deficits in amygdaloid complex in Alzheimer's disease and dementia with Lewy bodies. Acta Neuropathol 2006; 111:115-125.

10. Bierer LM, Haroutunian V, Gabriel S, et al. Neurochemical correlates of dementia severity in Alzheimer's disease: Relative importance of the cholinergic deficits. J Neurochem 1995;64:749-760.

11. Overshott R, Burns A. Treatment of dementia. J Neurol Neurosurg Psychiatry 2005;76(Suppl 5):v53-v59.

12. National Institute for Health and Clinical Excellence 2007, Alzheimer's disease-donepezil, galantamine, rivastigmine (review) and memantine. Technology appraisals TAl11. London: NICE. 2007. http://www.nice.org.uk/TA1 11 [Accessed March 30, 2010].

13. Raina P, Santaguida P, Ismaila A, et al. Effectiveness of cholinesterase inhibitors and memantine for treating dementia: Evidence review for a clinical practice guideline. Ann Intern Med 2008;148:379-397.

14. Kurz A, Van Baelen B. Ginkgo biloba compared with cholinesterase inhibitors in the treatment of dementia: A review based on meta-analyses by the cochrane collaboration. Dement Geriatr Cogn Disord 2004; 18:217-226.

15. Wilcock GK, Birks J, Whitehead A, Evans SJ. The effect of selegiline in the treatment of people with Alzheimer's disease: A meta-analysis of published trials. Int $J$ Geriatr Psychiatry 2002; 17:175-183.

16. Tariot PN, Federoff HJ. Current treatment for Alzheimer disease and future prospects. Alzheimer Dis Assoc Disord 2003;17(Suppl 4):S105-S113.

17. Sano M, Ernesto C, Thomas RG, et al. A controlled trial of selegiline, alpha-tocopherol, or both as treatment for Alzheimer's disease. The Alzheimer's disease Cooperative Study. N Engl J Med 1997;336:1216-1222.

18. Matveeva IA. Action of dimebon on histamine receptors. Farmakol Toksikol 1983;46:27-29.

19. Shadurskaia SK, Khomenko AI, Pereverzev VA, Balaklevskiı AI. Neuromediator mechanisms of the effect of the antihistamine agent dimebone on the brain. Biull Eksp Biol Med 1986;101:700-702.

20. Lermontova NN, Lukoyanov NV, Serkova TP, Lukoyanova EA, Bachurin SO. Dimebon improves learning in animals with experimental Alzheimer's disease. Bull Exp Biol Med 2000;129:544-546.

21. Bachurin S, Bukatina E, Lermontova N, et al. Antihistamine agent Dimebon as a novel neuroprotector and a cognition enhancer. Ann N Y Acad Sci 2001;939: 425-435.

22. Lermontova NN, Redkozubov AE, Shevtsova EF, Serkova TP, Kireeva EG, Bachurin SO. Dimebon and tacrine inhibit neurotoxic action of beta-amyloid in culture and block L-type $\mathrm{Ca}(2+)$ channels. Bull Exp Biol Med 2001;132:1079-1083.

23. Bachurin SO, Shevtsova EP, Kireeva EG, Oxenkrug GF, Sablin SO. Mitochondria as a target for neurotoxins and neuroprotective agents. Ann N Y Acad Sci 2003;993: 334-344; discussion 345-349.

24. Grigorev VV, Dranyi OA, Bachurin SO. Comparative study of action mechanisms of dimebon and memantine on AMPA- and NMDA-subtypes glutamate receptors in rat cerebral neurons. Bull Exp Biol Med 2003;136:474-477.

25. Wu J, Li Q, Bezprozvanny I. Evaluation of Dimebon in cellular model of Huntington's disease. Mol Neurodegener 2008;3:15, doi:10.1186/1750-1326-3-15.

26. Schaffhauser H, Mathiasen JR, Dicamillo A, et al. Dimebolin is a 5-HT(6) antagonist with acute cognition enhancing activities. Biochem Pharmacol 2009;78: 1035-1042.

27. Ivachtchenko AV, Frolov EB, Mitkin OD, et al. Synthesis and biological evaluation of novel gamma-carboline analogues of Dimebon as potent 5-HT6 receptor antagonists. Bioorg Med Chem Lett 2009;19:3183-3187.

28. Gandy S, Cirrito J, Steele J, et al. A clinically promising drug for Alzheimer disease, regulates amyloid-beta metabolism in cultured cells, in isolated nerve terminals, and in the interstitial fluid of the living rodent brain. ICAD 2009 Vienna Presentation \#: S4-04-06.

29. Yamashita M, Nonaka T, Arai T, et al. Methylene blue and dimebon inhibit aggregation of TDP-43 in cellular models. FEBS Lett 2009;583:2419-2424.

30. ICAD Submitted Abstract \#P1-254. A safety, tolerability and pharmacokinetic study of dimebon in patients with Alzheimer's disease already receiving donepezil. Poster Session. July 12, 2009: 12:30-3:00 p.m. P Tariot Presenter. 2009 International Conference on Alzheimer's Disease (ICAD), Vienna, Austria. July 2009;1 1-160.

31. Rosen WG, Mohs RC, Davis KL. A new rating scale for Alzheimer's disease. Am J Psychiatry 1984;141:1356-1364.

32. Birks JS, Harvey R. Donepezil for dementia due to Alzheimer's disease. The Cochrane Database of Systematic Reviews 2003:CD001190.

33. Steele JW, Kim SH, Cirrito JR, et al. Acute dosing of latrepirdine (DimebonTM), a possible Alzheimer therapeutic, elevates extracellular amyloid-beta levels in vitro and in vivo. Mol Neurodegener 2009;4:51.

34. Golubeva MI, Shashkina LF, Prŏnova VA, Fedorova EA, Nechushkina LV. Preclinical study of the safety of the 
antihistaminic preparation dimebon. Farmakol Toksikol 1985;48:114-119.

35. Roegge CS, Perraut C, Hao X, Levin ED. Histamine Hl receptor involvement in prepulse inhibition and memory function: relevance for the antipsychotic actions of clozapine. Pharmacol Biochem Behav 2007;86: 686-692.

36. Masuoka T, Kamei C. Role of hippocampal Hl receptors in radial maze performance and hippocampal theta activity in rats. Brain Res Bull 2007;73:231-237. 